\title{
Sex differences in association between cognitive impairment and clinical correlates in Chinese patients with first-episode drug-naïve schizophrenia
}

\author{
Na Zhao ${ }^{1}$, Xiao Hong Wang ${ }^{1}$, Chuan Yi Kang ${ }^{1}$, Yue Zheng ${ }^{1}$, Li Ying Yang ${ }^{1}$, Tie Feng Guan², Yun Xia Bai ${ }^{2}$, Ran Wei ${ }^{3}$, \\ Hunter C. Hinman ${ }^{4}$ and Xiang Yang Zhang ${ }^{5,6^{*}}$ (1)
}

\begin{abstract}
Background: Schizophrenia is a complex mental illness with significant sex differences. Cognitive impairment is common in patients with schizophrenia, even in remission. This study was designed to examine the sex differences in the relationship between cognitive impairment and clinical correlations with first-episode drug-naïve (FEDN) schizophrenia.

Methods: 93 FEDN patients (male/female $=45 / 48$ ) and 160 controls (male/female $=74 / 86$ ) were enrolled to compare the sex differences in cognitive functions measured by the MATRICS Consensus Cognitive Battery (MCCB). Positive and Negative Syndrome Scale (PANSS) and Hamilton Depression Scale (HAMD) were used to evaluate patients' clinical symptoms. We compared cognitive impairment with sociodemographic characteristics and measures of different genders, as well as group-by-sex interactions.

Results: Our results showed that male patients had significantly lower scores for symbol coding, digital sequence, and verbal learning than female patients, while the healthy controls showed similar sex differences. In female patients, multiple linear regression analysis confirmed that PANSS negative symptoms and general psychopathology scores, HAMD total score, and education level were independent contributors to MCCB total score. In male patients, only education was an independent contributor to MCCB total score.
\end{abstract}

Conclusions: These findings revealed significant sex differences in cognitive impairments and clinical symptoms in FEDN, which will be worthy of a follow-up study of schizophrenia in the future.

Keywords: Cognition, First-episode drug-naïve patients, MCCB, Schizophrenia, Sex difference

\section{Introduction}

Schizophrenia is a complex neuropsychiatric disease with noticeable sex differences. There is growing evidence that sex differences are present in almost all aspects

*Correspondence: zhangxy@psych.ac.cn

${ }^{5}$ CAS Key Laboratory of Mental Health, Institute of Psychology, Chinese Academy of Sciences, Beijing, China

Full list of author information is available at the end of the article of schizophrenia, including demographics, symptoms, social functioning, and treatment responses [1]. A majority of studies have shown that women have a later age of onset, fewer negative symptoms, and better reactions to antipsychotic drugs than men with schizophrenia [2], while men show more dysfunction and cognitive impairment, more substance abuse, and antisocial behavior [3]. Many studies have suggested that bio-psycho-social differences such as genetic susceptibility and abnormalities

c) The Author(s) 2021. This article is licensed under a Creative Commons Attribution 4.0 International License, which permits use, sharing, adaptation, distribution and reproduction in any medium or format, as long as you give appropriate credit to the original author(s) and the source, provide a link to the Creative Commons licence, and indicate if changes were made. The images or other third party material in this article are included in the article's Creative Commons licence, unless indicated otherwise in a credit line to the material. If material is not included in the article's Creative Commons licence and your intended use is not permitted by statutory regulation or exceeds the permitted use, you will need to obtain permission directly from the copyright holder. To view a copy of this licence, visit http://creativeco mmons.org/licenses/by/4.0/. The Creative Commons Public Domain Dedication waiver (http://creativecommons.org/publicdomain/ zero/1.0/) applies to the data made available in this article, unless otherwise stated in a credit line to the data. 
in neurodevelopment may play an important role [4-6]. Furthermore, cognitive dysfunction still exists during the remission period of schizophrenia, indicating that the clinical treatment effect is not sufficient in this domain, which constitutes the leading health, economic and social burden [7]. Therefore, the study of cognition and sex differences in patients with schizophrenia is essential for understanding the basis of neurobiological substrates.

Multiple pieces of evidence suggest that cognitive impairment is a core feature that often occurs in the lifetime of schizophrenia $[8,9]$, and involves a wide range of deficits, including language, attention, memory, processing speed, and executive function $[10,11]$. Cognitive dysfunction is significant because it is related to functional outcomes. Many studies support gender as a factor in controlling this correlation. Among 360 patients with first-episode psychosis, Li found a significant correlation between positive symptoms, short-term attention, and selective attention in male patients, while the correlation between memory and negative symptoms was more significant in female patients [12]. Another study showed that men generally performed poorly in verbal learning and memory, while women showed more extended responses to working memory tasks [13]. However, in a study by Ayesa-Arriola, there was no difference in neuropsychological performance between sexes during the first psychotic episode [14].

In China, there are few studies on sex differences and cognition of patients with schizophrenia. A recent study suggested that cognitive deficits are similar, and there is considerable heterogeneity between sexes in terms of symptoms and cognition [12]. In another present study, we found significant sex differences in many aspects of cognitive deficits with chronic schizophrenia [15]. Previous research from our group selected schizophrenia patients with or without diabetes and found that men performed poorly in immediate memory and delayed memory in both groups. Male patients with schizophrenia had the low supportive cognitive ability, regardless of whether they had diabetes [16]. Our study indicates that the first-episode drug-naive and chronically medicated patients with schizophrenia have cognitive dysfunction, showing that MATRICS Consensus Cognitive Battery (MCCB) is a sensitive measurement tool for measuring cognitive impairment in Chinese patients with schizophrenia. It also suggests that cognitive impairments exist in the early stage of schizophrenia [17], some of which may be more severe in the stage of chronic disease [18].

Currently, the research results are inconsistent, and the pathophysiological mechanisms at play are still not exact. These studies' shared and contradictory findings show the sex differences in cognitive impairment of patients with first-episode drug-naïve schizophrenia worthy of further research. There are many explanations for these differences related to genetic susceptibility and neurodevelopment, or bio-psycho-social factors [19-22]. Besides, culture may also play an essential role in sex differences in schizophrenia [2, 23, 24]. Medication may also affect the impact of cognitive function on the treatment outcome [6]. These differences can be better observed by excluding drug interventions in patients with first-episode drug-naïve schizophrenia.

To the best of our knowledge, there are few studies on the sex differences in cognitive impairment in first-episode drug-naïve schizophrenia. Therefore, the purpose of this study is to explore: (1) whether Chinese patients with FEDN schizophrenia had cognitive impairment compared to healthy controls; (2) whether cognitive impairment in schizophrenia showed sex differences; and (3) whether the sex differences in cognitive impairment is significantly correlated with clinical symptoms or general characteristics.

\section{Methods \\ Participants and study setting}

A total of 389 subjects were enrolled in this study, including 200 FEDN schizophrenia patients and 189 normal controls. And then, 107 patients and 29 controls were eventually excluded due to incomplete data $\left(N_{\text {controls }}=12\right)$, incomplete assessment of PANSS $\left(N_{\mathrm{pa}-}\right.$ tients $=30$ ), and incomplete cognitive assessment of $\operatorname{MCCB}\left(N_{\text {patients }}=78, N_{\text {controls }}=17\right)$; there was one patient who missed both PANSS and MCCB assessment. Finally, 93 schizophrenia patients and 160 normal controls were included in the analysis. The study was approved by the Institutional Review Board of Beijing HuiLongGuan Hospital. The informed consent form was written before their inclusion.

According to the Diagnostic and Statistical Manual of Mental Disorders (DSM-IV), the sample included patients ranging from 16 to 60 years old who met the diagnosis of schizophrenia according to the Diagnostic and Statistical Manual of Mental Disorders (DSM-IV). Two independent psychiatrists diagnosed each patient. All patients were first-time. They also met the following criteria: Han nationality, the duration of symptoms is less than 60 months, and no antipsychotic drugs were taken before this treatment. Individuals with other mental illnesses were excluded from this study.

The subjects of the control group came from the local community in Beijing. The interview was used to assess the status of the subjects to meet the requirements of this study. None of them had a family history of psychotic disorder. All the control cases were Han nationality, and 160 normal controls were recruited from nearby during the same period, including 74 males and 86 females. 


\section{Measures}

The subjects were evaluated by a detailed questionnaire, including general condition, medical history, sociodemographic characteristics, and treatment stage. The Hamilton Depression Scale (HAMD) was used to evaluate depressive symptoms, and the Clinical Global Impression (CGI) was an overall assessment scale.

Positive and negative symptoms were assessed by the Positive and Negative Syndrome Scale (PANSS), conducted by two psychologists with more than 5 years of working experience. The psychologists administering PANSS were blinded to the control versus schizophrenia group status of the subjects. After that, the intermediate raters' correlation coefficient is kept above 0.8 in the repeated evaluation of PANSS throughout the research. Three subscale models were proposed, including positive symptom subscale $(\mathrm{P})$, negative symptom subscale $(\mathrm{N})$, and general psychopathology subscale (G).

MATRICS Consensus Cognitive Battery (MCCB) is approved by the FDA to evaluate cognitive deficiencies and is a feasible endpoint indicator for clinical trials [25]. MCCB selected ten sub-tests from more than 90 tests, representing seven cognitive domains. It includes six factors extracted from the multi-factor analysis of schizophrenic cognitive operations: Speed of Processing, Attention, Working Memory, Verbal Learning, Visual Learning, Reasoning, and Problem-solving. The seventh cognitive domain is Social Cognition, which is a neurocognitive intermediary that reflects functional outcomes. These tests have high test-retest reliability, and most of them are above 0.70. In 2008, Professor Yu Xin introduced MCCB into China and conducted normative research to adjust to Chinese populations. In 2012, he began to write a specification manual, and in 2014 the MCCB China Model Manual was published. The standardized $\mathrm{T}$ score for each subject is calculated, which accounts for inconsistency in translation and makes the MCCB an appropriate measure in China [26].

\section{Statistical analysis}

Demographic and clinical data were compared using variance (continuous variables) and Chi-square test (categorical variables). The term "Group" refers to the categorization of FEDN schizophrenia versus controls, and "Sex" refers to men versus women with FEDN schizophrenia and men versus women controls. When significance was found in ANOVA, the effect of age, education, smoking, and marital status was tested between the FEDN schizophrenia and the controls. To adjust the influence of these variables on cognition, analysis of covariance (ANCOVA) was further assessed between groups. For the cognitive comparisons, we compared the
MCCB total score and the effects of ten separate domains on group and sex, as well as group-by-sex interactions on each item. Associations between demographic, clinical characteristics, BMI, and MCCB total score and ten index scores were assessed by Pearson correlation coefficients in male and female patients separately. We compared the total score of MCCB with sociodemographic characteristics and measures of different genders. We used the Bonferroni corrections to adjust for multiple testing. Stepwise multivariate analysis using MCCB total score as the dependent variable was used to investigate the impact of a range of variables. Through the research of related factors, several influencing factors were identified. Seven items of education, BMI, HAMD total score, PANSS total score, N, G, P entered the model. For sex, $\mathrm{N}$ and $\mathrm{G}$ were in the model because they strongly correlate with PANSS total score. When forming multiple collinearities, the PANSS total score was not included in the equation. The other 6 items for both male and female groups were included in the multiple linear regression model. The statistical software package for statistical calculations was the Statistical Program for Social Sciences (SPSS, version 24.0). The statistical test was considered with a two-tailed test, and the significance was set at 0.05 level.

\section{Results \\ Demographic and clinical data}

A total of 93 cases of FEDN schizophrenia and 160 cases of normal controls were included in this study. The normal control group's age was older than that of the FEDN schizophrenia group $(43.54 \pm 12.01$ versus $26.41 \pm 8.01$, $p<0.001)$. The variables were comparable between the groups (all $p>0.05$ ). There were 45 males and 48 females in the FEDN schizophrenia group and 74 males and 86 females in the normal control group. There was no significant difference in gender distribution $(p=0.743)$.

Table 1 shows that male patients scored higher than female patients on PANSS total score, PANSS negative symptom and general psychopathology subscale scores, and HAMD total score (all $p<0.05$ ). However, the significant differences in smoking, PANSS negative symptom subscore, and HAMD total score did not pass the Bonferroni correction (Bonferroni corrected $p<0.05 / 8=0.00625)$. Smoking displayed gender differences in both the control and schizophrenia groups. Thus, we controlled for smoking in the following analyses.

\section{Comparison of cognitive function in groups and by sex}

Sex cognitive differences in the two groups are summarized in Table 2 on the MCCB total scores and all ten indexes. The control group scored higher than the 
Table 1 Demographic and clinical characteristic in FEDN schizophrenia patients by sex

\begin{tabular}{|c|c|c|c|c|}
\hline & $\begin{array}{l}\text { Male patients } \\
(n=45)\end{array}$ & $\begin{array}{l}\text { Female patients } \\
(n=48)\end{array}$ & $F$ or $X^{2}$ & $p$ value \\
\hline Age (years) & $25.47 \pm 8.57$ & $27.29 \pm 7.43$ & 1.209 & 0.274 \\
\hline Education (years) & $12.49 \pm 3.25$ & $12.94 \pm 3.48$ & 0.411 & 0.523 \\
\hline Nonsmoker/smoker & $35 / 10$ & $47 / 1$ & 9.032 & $0.003^{* *}$ \\
\hline Married/others & $8 / 37$ & $11 / 37$ & 0.377 & 0.539 \\
\hline Body mass index (BMI) & $22.16 \pm 4.20$ & $21.66 \pm 4.62$ & 0.295 & 0.588 \\
\hline \multicolumn{5}{|l|}{ PANSS } \\
\hline Positive symptom subscale & $25.29 \pm 7.75$ & $25.48 \pm 5.08$ & 0.020 & 0.888 \\
\hline Negative symptom subscale & $22.16 \pm 8.96$ & $18.02 \pm 6.20$ & 6.673 & $0.011^{*}$ \\
\hline General psychopathology subscale & $46.18 \pm 13.35$ & $38.31 \pm 6.31$ & 13.467 & $<0.001^{* *}$ \\
\hline Total score & $93.62 \pm 22.86$ & $81.81 \pm 12.30$ & 9.791 & $0.002^{* *}$ \\
\hline CGl total score & $5.47 \pm 0.84$ & $5.52 \pm 0.77$ & 0.105 & 0.747 \\
\hline HAMD total score & $18.67 \pm 12.47$ & $12.65 \pm 9.13$ & 7.123 & $0.009^{* *}$ \\
\hline
\end{tabular}

${ }^{*} p<0.05,{ }^{* *} p<0.01$.

Table 2 Comparison of neuropsychological tests between normal controls and FEDN schizophrenia (between sex)

\begin{tabular}{|c|c|c|c|c|c|c|c|c|}
\hline \multirow{2}{*}{$\begin{array}{l}\text { Cognitive } \\
\text { domains }\end{array}$} & \multirow{2}{*}{$\begin{array}{l}\text { Cognitive } \\
\text { tests }\end{array}$} & \multicolumn{2}{|c|}{ Normal controls } & \multicolumn{2}{|c|}{ FEDN schizophrenia } & \multirow{2}{*}{$\begin{array}{l}\text { Diagnosis } F \\
\text { (p-value) }\end{array}$} & \multirow{2}{*}{$\begin{array}{l}\text { Sex } F \\
\text { ( } p \text {-value) }\end{array}$} & \multirow{2}{*}{$\begin{array}{l}\text { Diagnosis } \times \text { sex } \\
F \\
\text { (p-value) }\end{array}$} \\
\hline & & $\operatorname{Male}(n=74)$ & Female $(n=86)$ & Male $(n=45)$ & $\operatorname{Female}(n=48)$ & & & \\
\hline \multirow[t]{3}{*}{$\begin{array}{l}\text { Speed of } \\
\text { processing }\end{array}$} & $\begin{array}{l}\text { Category flu- } \\
\text { ency }\end{array}$ & $56.8 \pm 13.1$ & $52.0 \pm 12.2$ & $52.8 \pm 9.2$ & $51.5 \pm 9.7$ & $2.241(0.136)$ & $3.977(0.047)$ & $1.346(0.247)$ \\
\hline & Symbol coding & $57.7 \pm 9.4^{*}$ & $55.9 \pm 11.6$ & $38.4 \pm 11.0^{*}++$ & $43.5 \pm 9.7^{++}$ & $132.753(<0.001)$ & $1.447(0.230)$ & $6.354(0.012)$ \\
\hline & Trail Making A & $56.4 \pm 8.2$ & $53.8 \pm 9.6$ & $45.5 \pm 6.8^{++}$ & $47.3 \pm 7.3^{++}$ & $64.223(<0.001)$ & $0.151(0.698)$ & $4.043(0.045)$ \\
\hline Attention & CPT-IP & $55.2 \pm 7.9$ & $53.5 \pm 8.6$ & $40.4 \pm 9.7^{++}$ & $44.3 \pm 9.5^{++}$ & $108.633(<0.001)$ & $0.845(0.359)$ & $6.079(0.014)$ \\
\hline \multirow[t]{2}{*}{$\begin{array}{l}\text { Working } \\
\text { memory }\end{array}$} & $\begin{array}{l}\text { Spatial span } \\
\text { total }\end{array}$ & $60.7 \pm 11.4$ & $55.1 \pm 11.9$ & $43.7 \pm 12.1^{++}$ & $48.1 \pm 13.2^{++}$ & $58.608(<0.001)$ & $0.170(0.681)$ & $10.297(0.002)$ \\
\hline & $\begin{array}{l}\text { Digital } \\
\text { sequence }\end{array}$ & $60.2 \pm 10.5$ & $54.4 \pm 10.5$ & $46.0 \pm 10.2^{*++}$ & $50.8 \pm 10.1$ & $43.065(<0.001)$ & $0.138(0.711)$ & $14.873(<0.001)$ \\
\hline Verbal learning & HVLT-R total & $59.8 \pm 8.8$ & $56.3 \pm 10.3$ & $46.7 \pm 12.5^{*}++$ & $52.3 \pm 9.3^{+}$ & $41.215(<0.001)$ & $0.654(0.419)$ & $11.823(0.001)$ \\
\hline Visual learning & BVMT-R total & $57.8 \pm 8.2^{*}$ & $54.8 \pm 10.4$ & $49.1 \pm 9.5^{++}$ & $46.1 \pm 10.0^{++}$ & $49.165(<0.001)$ & $5.762(0.017)$ & $0.000(0.994)$ \\
\hline $\begin{array}{l}\text { Reasoning and } \\
\text { problem } \\
\text { solving }\end{array}$ & $\begin{array}{l}\text { Mazes (NAB) } \\
\text { total }\end{array}$ & $62.4 \pm 7.7^{* *}$ & $56.4 \pm 11.0$ & $48.9 \pm 10.3^{++}$ & $46.6 \pm 9.6^{++}$ & $83.328(<0.001)$ & $10.701(0.001)$ & $2.130(0.146)$ \\
\hline \multirow{2}{*}{$\begin{array}{l}\text { Social cogni- } \\
\text { tion }\end{array}$} & MSCEIT & $51.8 \pm 8.8$ & $51.0 \pm 8.3$ & $47.7 \pm 11.9^{+}$ & $51.2 \pm 11.1$ & $2.432(0.120)$ & $1.112(0.293)$ & $2.740(0.099)$ \\
\hline & $\begin{array}{l}\text { Total MCCB } \\
\text { scores }\end{array}$ & $63.0 \pm 10.6$ & $57.2 \pm 12.4$ & $44.2 \pm 10.0^{++}$ & $47.6 \pm 9.7^{++}$ & $97.977(<0.001)$ & $0.665(0.416)$ & $10.234(0.002)$ \\
\hline
\end{tabular}

${ }^{*}$ Indicates the comparison between males and females in FEDN schizophrenia or in the controls: ${ }^{*} p<0.05,{ }^{* *} p<0.01$

+ Indicates the comparison between FEDN schizophrenia and the controls in males or females: ${ }^{+} p<0.05,{ }^{++} p<0.01$

FEDN schizophrenia group in MCCB total score, Symbol coding, Trail Making A, CPT-IP, Spatial span total, Digital sequence, HVLT-R total, BVMT-R total, Mazes (NAB) total (all $p<0.001)$. Statistical significance was not reached in two areas: Category fluency $(p=0.136)$ and MSCEIT $(p=0.120)$. In the FEDN schizophrenia group, women performed better than men in Symbol coding, Digital sequence, and HVLT-R total $(p<0.05)$.
However, there was no sex difference in the other cognitive functions. After controlling for age, smoking, and education, these differences remained significant.

Moreover, multivariate analysis of covariance showed a diagnosis $\times$ sex interaction effect for all cognitive domains. To break down the two-way interaction, we examined patients and controls grouped by sex separately. Sex differences were found in Category 
fluency, BVMT-R total, and Mazes (NAB) total score. The MCCB 6 indexes and total scores showed diagnosis-by-sex interactions, including Symbol coding, Trail Making A, CPT-IP, Spatial span total, Digital sequence and HVLT-R total scores (all $p<0.05$ ). However, the significant differences in Symbol coding, Trail Making $\mathrm{A}$, and CPT-IP did not pass the Bonferroni correction (Bonferroni corrected $p<0.05 / 11=0.0045$ ).

\section{Correlation between cognitive function and clinical phenotypes in FEDN schizophrenia patients}

Table 3 shows the relationships between multiple clinical characteristics and cognitive deficits, separated by sex. In male patients, Pearson correlation analysis showed significant positive associations between education and multiple cognitive variables. Furthermore, Trail Making A, CPT-IP, Spatial span total, and Mazes (NAB) total score were significantly and negatively associated with the Positive symptom subscale. Only MSCEIT had a negative association with the Negative symptom subscale. Category fluency, Trail Making A, CPT-IP, Mazes (NAB) total score were associated with the General psychopathology subscale. PANSS total score displayed a significantly negative relationship to Trail Making A, CPT-IP, Mazes (NAB) total score, and MCCB total score. The MCCB total score had a significant association with education and PANSS total score. Further multivariate regression analyses showed that education was independently associated with the MCCB total score (beta $=0.407, t=2.726, p=0.010$ ).

In female patients, Pearson correlation showed significant positive correlations between education and MCCB ten indexes and MCCB total score (all $p<0.05$ ). Except for Symbol coding, Trail Making A, Digital sequence, BVMT-R total, and Mazes (NAB) total score, the other cognitive domains were negatively associated with the Negative symptom subscale. Trail Making A, HVLT-R total, MSCEIT, and MCCB total score were negatively associated with the General psychopathology subscale. PANSS total score was significantly negatively related to Tail Making A, CPT-IP, Digital sequence, HVLT-R total, MSCEIT, and MCCB total score. Finally, we found an association between $\mathrm{MCCB}$ total score and education, PANSS negative symptom and general psychopathology subscale scores, and PANSS total score. Further multivariate regression analyses showed that the following variables were independently associated with the MCCB total score: education (beta $=0.425, t=3.730, p=0.001$ ), the PANSS Negative symptom subscale (beta $=-0.308$, $t=-2.561, p=0.014)$, the PANSS General psychopathology subscale (beta $=-0.319, t=-2.145$, $p=0.038)$, HAMD total score $($ beta $=-0.299$, $t=-2.422, p=0.020$ ).

\section{Discussion}

To the best of our knowledge, this is the first study of sex differences in cognitive impairment with first-episode drug-naïve schizophrenia in China. The main finding of our current study is that patients with schizophrenia have demonstrable cognitive dysfunction. Additionally, there were apparent sex differences in cognitive impairment with FEDN schizophrenia in this sample. Male patients performed worse than female patients in symbol coding, digital sequence, and verbal learning. Interestingly, we also found six indexes and MCCB total score that showed diagnosis-by-sex interactions, belonging to the speed of processing, attention, working memory, and verbal learning. Lastly, sex differences in cognitive impairment were significantly related to multiple clinical symptoms and general characteristics (Table 3).

A great deal of research and analysis has been devoted to evaluating the neuropsychologic disorders suffered by schizophrenia patients in several cognitive fields. Language ability, executive function, attention, and the ability to filter irrelevant stimuli are all impaired. Working memory and executive function of patients with schizophrenia are also impaired [27-29]. Consistent with this finding, several cognitive deficits have been reported in adolescent schizophrenia. For example, Victoria et al. used MCCB to examine cognitive impairment samples in Mexican adolescents with schizophrenia. After 3 and 6 months of treatment, all domains were improved except for social cognition [30]. In recent years, oxytocin (OXT) has emerged as a novel strategy for treating social cognitive and social behavioral deficits in schizophrenia-spectrum disorders, an intriguing prospect from both the evolutionary perspective and the neurodevelopmental-cognitive model. Therefore more research is needed to determine the utility of OXT as a treatment option or adjuvant therapy for schizophrenia [31, 32]. Other preliminary studies have shown that male patients with chronic schizophrenia have more severe cognitive impairment than female patients in immediate memory and delayed memory. However, these differences were not found in language, visuospatial or attention indices [33]. The difference between schizophrenia and normal control is the result of a combination of factors. An indepth study of these differences can help to guide the treatment in the future.

Stress has been shown to damage memory that leads to cognitive impairment in multiple clinical contexts. Corticotropin-releasing factor (CRF) likely plays a primary role in mediating stress mnemonic dysfunction. Wiersielis assessed whether the projection of CRF into the medial 


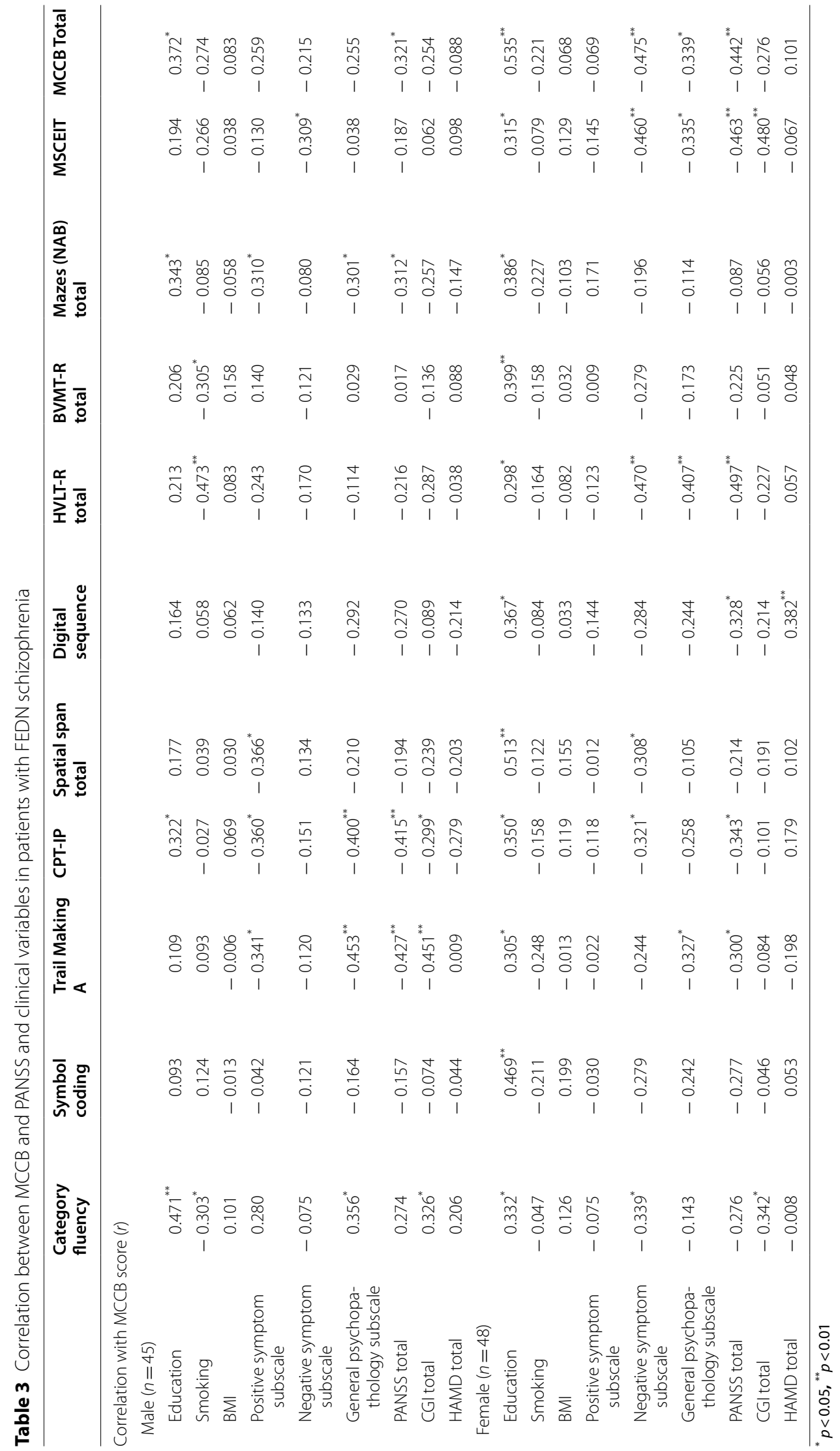


septum (MS) of the hippocampus would affect memory formation in male and female rats [34]. Interestingly, the results indicated that males are more vulnerable than females to be affected by the memory impairment caused by CRF in the MS. This may explain why schizophrenia is more common in men and why men usually show more significant cognitive impairment. In men and women, CRF1 antagonists can prevent MS-mediated memory impairment caused by high CRF levels, which may be related to stressful events. Collectively, CRF1 antagonists may be a viable option for treating cognitive impairment in stressed individuals with mental disorders.

Another possible reason for the demonstrated sex differences in the clinical presentation of schizophrenia may be the biological differences in sex hormones. Women often display more mild symptoms, and one hypothesis is that estrogen may have a protective effect on schizophrenia. The relationship between estrogen and BDNF, NMDA receptors, GABA receptors, and the luteinizing hormone may be an essential way to understand sex differences [35]. Estrogen has therapeutic effects and exerts neuroprotective effects, including anti-excitotoxicity and oxidation. Another prominent female gonadal hormone is progesterone, and available data indicate a critical modulator in regulating the central system through the dopaminergic system [36].

Although women and men with schizophrenia show similar neuropsychological damage [37], the available evidence strongly supports sex differences in neuropsychological performance. Female patients have a later age of onset, better functional outcomes, less adverse symptomatology, cognitive impairment, and more severe positive symptoms [38]. Nevertheless, consistent with the studies mentioned above, our study showed that male patients with schizophrenia performed worse in symbol coding, digital sequence, and verbal learning in the firstepisode schizophrenia group. However, there were no gender differences in other cognitive functions. We also found that men are significantly worse than women on PANSS total score, Negative symptom scale, General psychopathology scale, and HAMD total score. Consistent with this finding, Li found sex differences in first-episode psychosis from 360 patients in Hong Kong participants diagnosed with mental illness for the first time between the ages of 26 and 55. They had received antipsychotic treatment for less than 12 months. In women, memory was significantly associated with onset age, negative symptoms, and side effects. Selective attention was correlated with the age of onset and education in men and positive symptoms and short-term symptoms [12].

For sex differences in cognitive deficits, Zhang enrolled 248 patients with chronic schizophrenia and 188 healthy controls. Using the Repeatable Battery for the Assessment of Neuropsychological Status (RBANS), the brain-derived neurotrophic factor (BDNF) levels were lower in patients with chronic schizophrenia. Furthermore, male patients with schizophrenia had significantly lower BDNF and more unsatisfactory memory performance than their female counterparts, and in female patients, BDNF correlated significantly with immediate and delayed memory. There was no gender difference in the normal control group [38]. In addition, the impairment of visual perceptual organization ability is a cognitive defect repeatedly observed in patients with schizophrenia, but we did not find differences in visual learning between genders. There are inconsistencies in the literature on sex differences in these cognitive deficits. A Spanish study enrolled 74 female and 86 male participants who suffered from the first episode of psychosis. Although women scored higher than men on verbal memory, men scored higher than women on reaction time, visual memory, and planned tasks. In that study, there were no gender-group interactions in any of the neuropsychological tests [14].

There are some limitations to this study. First, this cross-sectional design cannot demonstrate the longitudinal course of illness that long-term research might. Second, the patients' age in the first-episode drug-naïve schizophrenia group was younger than that of the control group. The inclusion criteria of symptoms less than 60 months and the antipsychotic naivete likely skewed the age younger in this group. Nevertheless, the effect of these data on cognitive function is more useful and less confounded than in patients who have received longterm treatment for schizophrenia. Third, although we initially enrolled more patients, the sample size diminished due to exclusion criteria, incorrect questionnaires, and incomplete cognitive assessment. Finally, we chose MCCB as the cognitive testing, which may have data bias. More measurements and laboratory data need to be collected to evaluate better cognitive impairment and sex differences in patients with schizophrenia. In the future, the sample size should ideally be expanded, characteristics such as education controlled for, and longitudinal studies should be conducted to track cognitive changes.

\section{Conclusions}

Our results suggest that there is cognitive dysfunction in the schizophrenia group. Specifically, men with FEDN schizophrenia have lower cognitive abilities than women in symbol coding, digital sequence, and verbal learning. Future studies should also consider the possible causes of sex differences in patients with schizophrenia, and appropriate strategies should be implemented, especially 


\section{in evaluating the influence of treatment and longitudinal course of schizophrenia.}

\section{Acknowledgements}

We would like to thank all participants and all co-authors in the study.

\section{Authors' contributions}

NZ, XHW, CYK, TFG, XYZ were responsible for study design, statistical analysis, and manuscript preparation. CYK, YZ, LYY were responsible for recruiting the patients, performing the clinical rating, and collecting the samples. RW, TFG, $Y X B, H C H$ were involved in evolving the ideas and editing the manuscript. All authors have contributed to and have approved the final manuscript.

\section{Funding}

This work was supported by the research and innovation fund of the First Affiliated Hospital of Harbin Medical University [Grant Number 2020B07].

\section{Availability of data and materials}

The datasets used and/or analyzed during the current study are available from the corresponding author on reasonable request.

\section{Declarations}

\section{Ethics approval and consent to participate}

The study was approved by the Institutional Review Board of Beijing HuiLongGuan Hospital. All participants have to give written informed consent before taking part in this study.

\section{Consent for publication}

The authors have obtained consent to publish from the participant to report patient data.

\section{Competing interests}

The authors declare that they have no competing interests.

\begin{abstract}
Author details
${ }^{1}$ Department of Psychiatry, The First Affiliated Hospital of Harbin Medical University, Harbin, Heilongjiang Province, China. ${ }^{2}$ Psychological Clinic, The First Hospital of Yichun, Yichun, Heilongjiang Province, China. ${ }^{3}$ Department of Clinical Psychology, Suzhou Guangji Hospital, The Affiliated Guangji Hospital of Soochow University, Suzhou, Jiangsu Province, China. ${ }^{4}$ Department of Psychiatry and Behavioral Sciences, The University of Texas Health Science Center At Houston, Houston, TX, USA. ${ }^{5}$ CAS Key Laboratory of Mental Health, Institute of Psychology, Chinese Academy of Sciences, Beijing, China. ${ }^{6}$ Department of Psychology, University of Chinese Academy of Sciences, Beijing, China.
\end{abstract}

\section{Received: 25 December 2020 Accepted: 12 April 2021}

Published online: 21 April 2021

\section{References}

1. Riecher-Rossler A, Butler S, Kulkarni J. Sex and gender differences in schizophrenic psychoses-a critical review. Arch Womens Ment Health. 2018;21(6):627-48.

2. Caqueo-Urizar A, Fond G, Urzua A, Boyer L. Gender differences in schizophrenia: a multicentric study from three Latin-America countries. Psychiatry Res. 2018;266:65-71.

3. Seeman MV. Does gender influence outcome in schizophrenia? Psychiatr Q. 2019;90(1):173-84.

4. Dewan MJ. The psychology of schizophrenia: implications for biological and psychotherapeutic treatments. J Nerv Ment Dis. 2016;204(8):564-9.

5. Micoulaud-Franchi JA, Faugere M, Boyer L, Fond G, Richieri R, Faget C, Cermolacce M, Philip P, Vion-Dury J, Lancon C. Elevated C-reactive protein is associated with sensory gating deficit in schizophrenia. Schizophr Res. 2015;165(1):94-6.

6. Li X, Yuan X, Kang Y, Pang L, Liu Y, Zhu Q, Lv L, Huang XF, Song X. A synergistic effect between family intervention and rTMS improves cognitive and negative symptoms in schizophrenia: a randomized controlled trial. J Psychiatr Res. 2020;126:81-91.

7. Mihaljevic-Peles A, Bajs Janovic M, Sagud M, Zivkovic M, Janovic S, Jevtovic S. Cognitive deficit in schizophrenia: an overview. Psychiatr Danub. 2019;31(Suppl 2):139-42.

8. Koshiyama D, Fukunaga M, Okada N, Yamashita F, Yamamori H, Yasuda Y, Fujimoto M, Ohi K, Fujino H, Watanabe Y, et al. Subcortical association with memory performance in schizophrenia: a structural magnetic resonance imaging study. Transl Psychiatry. 2018;8(1):20.

9. DeTore NR, Mueser KT, Byrd JA, McGurk SR. Cognitive functioning as a predictor of response to comprehensive cognitive remediation. J Psychiatr Res. 2019;113:117-24.

10. Vorackova V, Knytl P, Spaniel F, Sustova P, Renka J, Mohr P. Cognitive profiles of healthy siblings of first-episode schizophrenia patients. Early Interv Psychiatry. 2020.

11. Atake K, Nakamura T, Ueda N, Hori H, Katsuki A, Yoshimura R. The impact of aging, psychotic symptoms, medication, and brain-derived neurotrophic factor on cognitive impairment in japanese chronic schizophrenia patients. Front Psychiatry. 2018;9:232.

12. Li AWY, Hui CLM, Lee EHM, Chang WC, Chan SKW, Chen EYH. Gender differences in correlates of cognition in first-episode psychosis. Psychiatry Res. 2019;271:412-20.

13. Ittig S, Studerus E, Papmeyer M, Uttinger M, Koranyi S, Ramyead A, Riecher-Rossler A. Sex differences in cognitive functioning in at-risk mental state for psychosis, first episode psychosis and healthy control subjects. Eur Psychiatry. 2015;30(2):242-50.

14. Ayesa-Arriola R, Rodriguez-Sanchez JM, Gomez-Ruiz E, Roiz-Santianez R, Reeves LL, Crespo-Facorro B. No sex differences in neuropsychological performance in first episode psychosis patients. Prog Neuropsychopharmacol Biol Psychiatry. 2014;48:149-54.

15. Wei CW, Chen YQ, Ma M, Xiu MH, Zhang XY. Sex differences in the association of body mass index with symptoms and cognitive deficits in Chinese patients with chronic schizophrenia. Transl Psychiatry. 2020;10(1):18.

16. Zhang BH, Han M, Zhang XY, Hui L, Jiang SR, Yang FD, Tan YL, Wang ZR, Li $J$, Huang XF. Gender differences in cognitive deficits in schizophrenia with and without diabetes. Compr Psychiatry. 2015;63:1-9.

17. Strauss GP, Chapman HC, Keller WR, Koenig Jl, Gold JM, Carpenter WT, Buchanan RW. Endogenous oxytocin levels are associated with impaired social cognition and neurocognition in schizophrenia. J Psychiatr Res. 2019;112:38-43.

18. Wu JQ, Chen DC, Tan YL, Xiu MH, De Yang F, Soares JC, Zhang XY. Cognitive impairments in first-episode drug-naive and chronic medicated schizophrenia: MATRICS consensus cognitive battery in a Chinese Han population. Psychiatry Res. 2016;238:196-202.

19. Xiu MH, Li Z, Chen DC, Chen S, Curbo ME, Wu HE, Tong YS, Tan SP, Zhang $\mathrm{XY}$. Interrelationships between BDNF, superoxide dismutase, and cognitive impairment in drug-naive first-episode patients with schizophrenia. Schizophr Bull. 2020;46(8):1498-510.

20. Guan HY, Zhao JM, Wang KQ, Su XR, Pan YF, Guo JM, Jiang L, Wang YH, Liu HY, Sun SG, et al. High-frequency neuronavigated rTMS effect on clinical symptoms and cognitive dysfunction: a pilot double-blind, randomized controlled study in Veterans with schizophrenia. Transl Psychiatry. 2020;10(1):79.

21. Xia L, Yuan L, Du XD, Wang D, Wang J, Xu H, Huo L, Tian Y, Dai Q, Wei $\mathrm{S}$, et al. P50 inhibition deficit in patients with chronic schizophrenia: Relationship with cognitive impairment of MATRICS consensus cognitive battery. Schizophr Res. 2020;215:105-12.

22. Jirsaraie RJ, Sheffield JM, Barch DM. Neural correlates of global and specific cognitive deficits in schizophrenia. Schizophr Res. 2018;201:237-42.

23. Kirkbride JB, Hameed Y, loannidis K, Ankireddypalli G, Crane CM, Nasir M, Kabacs N, Metastasio A, Jenkins O, Espandian A, et al. Ethnic minority status, age-at-immigration and psychosis risk in rural environments: evidence from the SEPEA study. Schizophr Bull. 2017;43(6):1251-61.

24. Wang DM, Zhang GY, Du XD, Jia QF, Qian ZK, Yin GZ, Chen DC, Xiu MH, Ning YP, Huang $X B$, et al. Sex differences in the prevalence and clinical features of comorbid depressive symptoms in never-treated chinese patients with first-episode schizophrenia. J Clin Psychiatry. 2019. https:// doi.org/10.4088/JCP.19m12780.

25. Michalopoulou PG, Lewis SW, Drake RJ, Reichenberg A, Emsley R, Kalpakidou AK, Lees J, Bobin T, Gilleen JK, Pandina G, et al. Modafinil combined with cognitive training: pharmacological augmentation 
of cognitive training in schizophrenia. Eur Neuropsychopharmacol. 2015;25(8):1178-89.

26. Shi C, Kang L, Yao S, Ma Y, Li T, Liang Y, Cheng Z, Xu Y, Shi J, Xu X, et al. The MATRICS Consensus Cognitive Battery (MCCB): co-norming and standardization in China. Schizophr Res. 2015;169(1-3):109-15.

27. Trapp W, Dotterweich S, Hintner L, Wollny H, Lautenbacher S, Hajak G. Speed and capacity of working memory and executive function in schizophrenia compared to unipolar depression. Schizophr Res Cogn. 2017:10:1-6.

28. Yang YJ, Luo T, Zhao Y, Jiang SZ, Xiong JW, Zhan JQ, Yu B, Yan K, Wei B. Altered insulin-like growth factor-2 signaling is associated with psychopathology and cognitive deficits in patients with schizophrenia. PLOS ONE. 2020;15(3):e0226688.

29. Guimond S, Padani S, Lutz O, Eack S, Thermenos H, Keshavan M. Impaired regulation of emotional distractors during working memory load in schizophrenia. J Psychiatr Res. 2018;101:14-20.

30. Victoria G, Apiquian R, Rosetti MF, Ulloa RE. Cognitive impairment and its improvement after six months in adolescents with schizophrenia. Schizophr Res Cogn. 2019;17:100135.

31. Bartholomeusz CF, Ganella EP, Labuschagne I, Bousman C, Pantelis C. Effects of oxytocin and genetic variants on brain and behaviour: Implications for treatment in schizophrenia. Schizophr Res. 2015;168(3):614-27.

32. Veras AB, Getz M, Froemke RC, Nardi AE, Alves GS, Walsh-Messinger J, Chao MV, Kranz TM, Malaspina D. Rare missense coding variants in oxytocin receptor (OXTR) in schizophrenia cases are associated with early trauma exposure, cognition and emotional processing. J Psychiatr Res. 2018:97:58-64.
33. Han M, Huang XF, Chen DC, Xiu MH, Hui L, Liu H, Kosten TR, Zhang XY. Gender differences in cognitive function of patients with chronic schizophrenia. Prog Neuropsychopharmacol Biol Psychiatry. 2012;39(2):358-63.

34. Wiersielis KR, Ceretti A, Hall A, Famularo ST, Salvatore M, Ellis AS, Jang H, Wimmer ME, Bangasser DA. Sex differences in corticotropin releasing factor regulation of medial septum-mediated memory formation. Neurobiol Stress. 2019;10:100150

35. McGregor C, Riordan A, Thornton J. Estrogens and the cognitive symptoms of schizophrenia: possible neuroprotective mechanisms. Front Neuroendocrinol. 2017:47:19-33.

36. Sun J, Walker AJ, Dean B, van den Buuse M, Gogos A. Progesterone: The neglected hormone in schizophrenia? A focus on progesterone-dopamine interactions. Psychoneuroendocrinology. 2016;74:126-40.

37. Zanelli J, Morgan K, Dazzan P, Morgan C, Russo M, Pilecka I, Fearon P, Demjaha A, Doody GA, Jones PB, et al. Gender differences in neuropsychological performance across psychotic disorders-a multi-centre population based case-control study. PLoS ONE. 2013;8(10):e77318.

38. Zhang XY, Chen DC, Tan YL, Tan SP, Wang ZR, Yang FD, Xiu MH, Hui L, LV $\mathrm{MH}$, Zunta-Soares GB, et al. Gender difference in association of cognition with BDNF in chronic schizophrenia. Psychoneuroendocrinology. 2014;48:136-46.

\section{Publisher's Note}

Springer Nature remains neutral with regard to jurisdictional claims in published maps and institutional affiliations.
Ready to submit your research? Choose BMC and benefit from:

- fast, convenient online submission

- thorough peer review by experienced researchers in your field

- rapid publication on acceptance

- support for research data, including large and complex data types

- gold Open Access which fosters wider collaboration and increased citations

- maximum visibility for your research: over 100M website views per year

At BMC, research is always in progress.

Learn more biomedcentral.com/submissions 